\title{
Skull Base Chordomas and Chondrosarcomas
}

\author{
Natalia Kremenevski ${ }^{a}$ Sven-Martin Schlaffer ${ }^{a}$ Roland Coras ${ }^{b}$ \\ Thomas Mehari Kinfe ${ }^{\mathrm{a}}$ Thomas Graillon ${ }^{c}$ Michael Buchfelder ${ }^{\mathrm{a}}$ \\ ${ }^{a}$ Department of Neurosurgery, University of Erlangen-Nürnberg, Erlangen, Germany; \\ ${ }^{b}$ Institute of Neuropathology, University of Erlangen-Nürnberg, Erlangen, Germany; \\ 'Department of Neurosurgery, Aix-Marseille University, APHM, CHU Timone, Marseille, France
}

\section{Keywords}

Skull base - Chordoma . Chondrosarcoma - Diagnosis .

Therapy

\begin{abstract}
Skull base chordomas account for less than $0.2 \%$ and chondrosarcomas for less than $0.15 \%$ of all intracranial tumors. Although their clinical and imaging presentations are similar, they derive from different origins. Chordomas arise from embryonic remnants of the primitive notochord and chondrosarcomas from primitive mesenchymal cells or from the embryonic rest of the cranial cartilaginous matrix. Both entities are characterized by infiltration and destruction of the surrounding bone and soft tissue and a high locoregional recurrence rate. Chondrosarcomas, when treated with similar complex strategies, display a much better prognosis than chordomas. The overall survival is approximately $65 \%$ for chordomas and $80 \%$ for chondrosarcomas at 5 years and 30 and $50 \%$, respectively, at 10 years. Chordomas are divided into the following 3 histological types: classical (conventional), chondroid, and dedifferentiated. Chondrosarcomas have conventional, mesenchymal, clear cell, and dedifferentiated subgroups. Both tumor entities often present with nonspe-
\end{abstract}

karger@karger.com www.karger.com/nen

Karger!

(1) cific symptoms, and headaches are the most reported initial symptom. Computed tomography and magnetic resonance imaging are required to determine the tumor localization and the extent of tumor growth. The treatment philosophy is to maximize tumor resection, minimize morbidity, and preserve function. Neurosurgical approaches commonly used for the resection of intracranial chordomas and chondrosarcomas are transsphenoidal, transbasal, cranio-orbitozygomatic, transzygomatic extended middle fossa, transcondylar, and transmaxillary approaches. Chordomas and chondrosarcomas are not sensitive to chemotherapy and there are no approved drugs for their treatment. The present treatment concept is a combination of surgical resection with a maximal excision and preserving patients' quality of life by adjuvant radiotherapy for both chordomas and chondrosarcomas.

(C) 2020 S. Karger AG, Basel

\section{Introduction}

Chordomas and chondrosarcomas are a heterogeneous group of primary malignancies that develop within and invade the skull base region. They represent patholo- (c) 2020 S. Karger AG, Base
Natalia Kremenevski

Department of Neurosurgery, University of Erlangen-Nürnberg Schwabachanlage 6

natalia.kremenevskaja@uk-erlangen.de 
gies that exhibit a wide diversity of oncologic behavior. A standard classification is difficult to apply. It appears appropriate to divide the lesions according to their clinical presentation and radiologic characteristics. For this reason, chordomas and chondrosarcomas have been historically grouped together. However, these tumors are distinct clinicopathological entities and vary significantly in terms of their clinical outcome. Chordomas and chondrosarcomas are rare malignant tumors characterized by slow, destructive, and locally invasive growth. Chordomas arise from embryonic remnants of the primitive notochord with a molecular alteration preceding their malignant transformation. On the other hand, chondrosarcomas are considered to originate from primitive mesenchymal cells or from embryonic remnants of the cartilaginous matrix in the cranium. Furthermore, chordomas and chondrosarcomas share a high propensity for locoregional recurrence with infiltration and destruction of the surrounding bone and soft tissue. Although the metastatic potential of these malignancies is considered to be relatively low, distant metastases has been reported in patients with advanced disease. This is associated with a poor prognosis and a median survival of less than 12 months. Both of these tumors usually display slow growth patterns and cause gradual displacement of neurovascular structures, in turn leading to the manifestation of clinical signs and subsequent diagnosis. The complex structure of the cranial base, together with the close proximity to cranial nerves and vessels, represents a significant challenge in the management of these tumors. It ought to be noted that aggressive surgery is associated with a considerable risk of high morbidity and mortality. Herein, we present a review of the literature summarizing the epidemiology, histopathology, clinical signs, diagnosis and differential diagnosis, imaging characteristics, and various multimodal treatments with related clinical outcomes of skull base chordomas and chondrosarcomas.

\section{Epidemiology}

Skull base chordomas are rare malignancies and account for less than $0.2 \%$ of all intracranial neoplasms [1, 2]. Several large population-based studies have estimated the overall incidence rate of chordomas to be 0.08 per 100,000 persons per year [3-5]. They may occur in all age groups (although most cases are diagnosed during adulthood, with the mean age of affected person being in the fifth and sixth decades of life) [3], rarely affecting children and adolescents ( $<5 \%$ of all chordomas) [6]. The gender

Skull Base Chordomas and

Chondrosarcomas distribution has been reported to be nearly equal in skull base lesions. Chordomas have no known causative association with irradiation or other environmental factors. However, there is a very small percentage of cases displaying a familial pattern of inheritance.

Interestingly, chondrosarcomas also represent approximately $0.15 \%$ of all intracranial neoplasms [7] and constitute $6 \%$ of all skull base tumors $[8,9]$. The peak incidence occurs in the fourth and sixth decades of life with no gender predilection. In a study by Bloch et al. [10], 32\% of chondrosarcomas involved the clivus and $27 \%$ arose at the temporo-occipital junction. It ought to be noted that distant metastases are very rare for both of these intracranial tumors. The outcome is quite different between chordomas and chondrosarcomas, with the latter displaying a much better prognosis when treated with similar complex strategies.

\section{Histopathology}

\section{Chordomas}

The first macro- and microscopical description of chordomas was provided by the German physician and pathologist Rudolf Virchow [11]. He described on autopsy an incidental, small, slimy growth on the surface of the clivus. Since that time the intracellular, bubble-like vacuole cells referred to by Virchow [11] as "physaliferous" remain a distinguishing, if not pathognomonic, feature of chordomas. Another German pathologist, i.e., Hugo Ribbert, later proposed the term chordoma [12].

The following 3 histopathological types of chordomas have been identified: classic (conventional), chondroid, and dedifferentiated types [13-15]. The histopathological type of a chordoma predicts the prognosis of this tumor. The first 2 forms have a favorable long-term prognosis, with a 3-year overall survival rate of $90 \%$ [13]. The dedifferentiated subtype displays aggressive behavior and only a $60 \% 3$-year overall survival rate $[13,16]$.

A conventional (classic) chordoma consists of cords and islands of eosinophilic and clear vacuolated cells, also called "physaliphorous cells," suspended in a myxoidmucous matrix (Fig. 1a, b). The nuclei are round and uniform, although some exhibit considerable pleomorphism. A thin fibrous septum divides groups of these cells into lobules. This classic pattern of chordoma should not show evidence of chondroid or other mesenchymal tissue differentiation. The second type of chordoma or chondroid chordoma shows regions where the stroma resembles hyaline cartilage and neoplastic, sometimes phys- 


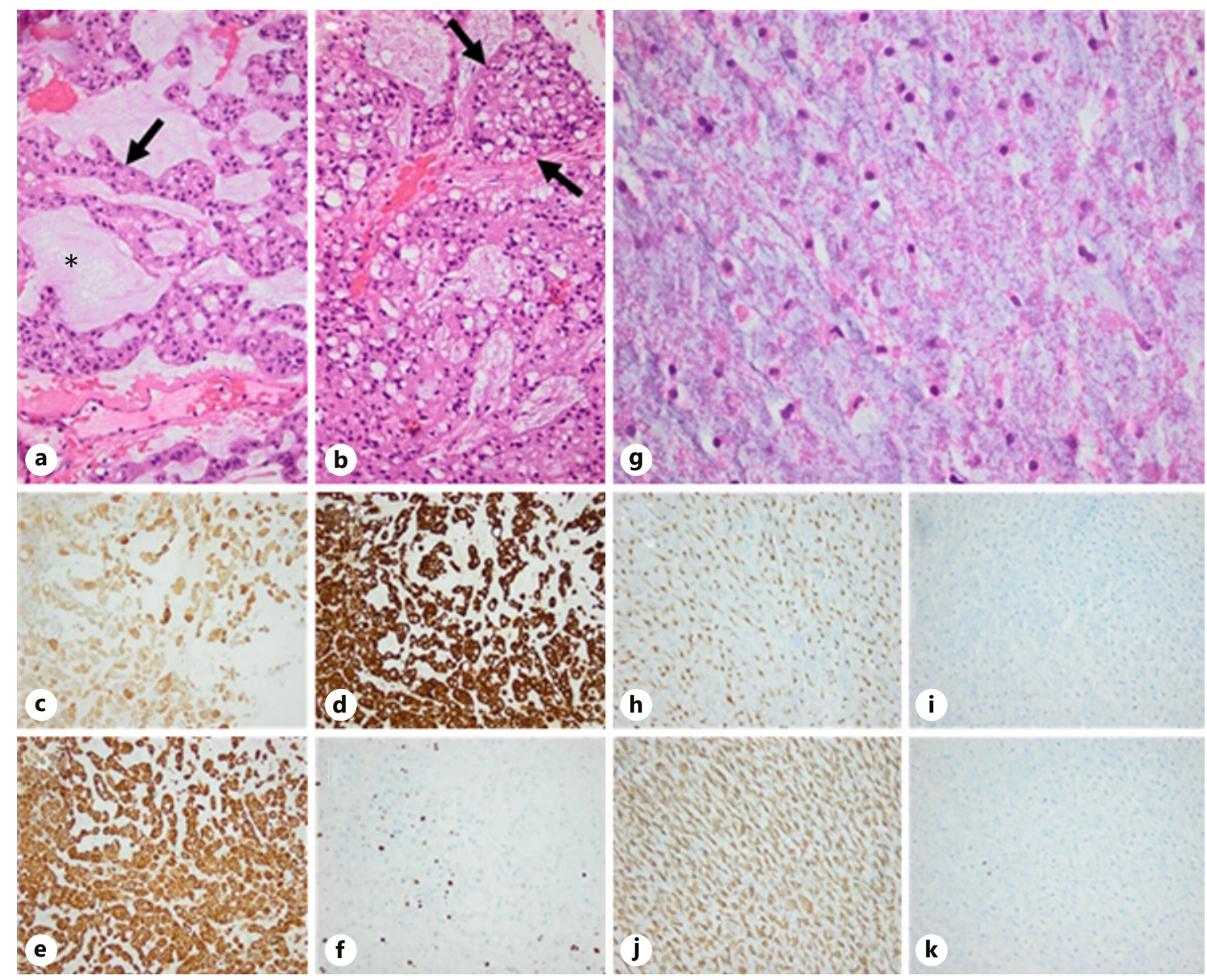

Fig. 1. Characteristic histologic features of chordomas (a-f) and chondrosarcomas $(\mathbf{g}-\mathbf{k})$. a, b HE staining of a chordoma showing epitheloid cells arranged in cords (arrow in a) and detectable extracellular mucin (asterisk in a). In other areas a lobular arrangement can be observed (arrows in b). Chordomas show a characteristic immunohistochemical expression of $\mathrm{S} 100$ (c), pan-cytokeratins (d), and vimentin (e). Moderate proliferation activity (Ki67 immunostaining in $\mathbf{f})$. $\mathbf{g}$ HE staining showing a well-differentiated chondrosarcoma (G1) with moderate cellularity without mitoses or necrosis. Chondrosarkomas show a characteristic immunohistochemical expression of $\mathrm{S} 100(\mathbf{h})$ and vimentin (j), while pancytokeratins (i) are not expressed. Low proliferation activity (Ki67 immunostaining in $\mathbf{k}$ ). aliphorous, cells grow in lacunae. The rare dedifferentiated chordomas are characterized by a frankly malignant, mesenchymal component and have a sarcomatoid appearance. They carry a very poor prognosis. Finally, on immunohistochemistry (Fig. 1c-e), chordomas stain positively for S100, vimentin, epithelial membrane antigen, and pan-cytokeratins [6, 17-20]. "Brachyury" is a new, recently discovered specific diagnostic marker for chordomas [21]. A high brachyury expression was found in chordoma tissue samples [22]. There is no correlation between brachyury expression and clinicopathological parameters in chordoma patients [23]. Other tumors do not show expression of this protein $[21,24]$. The determination of brachyury can therefore be used to differentiate tumors with a similar histology and geographical location [25]. However, some poorly differentiated and dedifferentiated areas of chordomas may display a loss of brachyury immunoreactivity $[21,24,26,27]$.

\section{Chondrosarcomas}

The first histological report of an intracranial chondrosarcoma was published in 1899 by the British biochemist and neuropathologist Sir Frederick Walker Mott [28]. Histologically, chondrosarcomas are characterized by an abundant hyaline type of cartilaginous stroma and the presence of a neoplastic chondrocyte population. The chondrocytes have an inconspicuous cytoplasm and a small, dark nucleus with fine chromatin (Fig. 1g). Infiltra- 
tion of the bony trabeculae is a histological feature of malignancy. Moreover, extension into the surrounding soft tissue may be observed $[29,30]$. Chondrosarcomas can be classified into the following 4 histological subgroups: conventional chondrosarcoma, mesenchymal chondrosarcoma, clear cell chondrosarcoma, and dedifferentiated chondrosarcoma $[31,32]$. It is well known that chondrosarcomas demonstrate recognizable histological grades of differentiation. Based on cellularity, mitotic activity, atypia, and nuclear size, the WHO introduced the following 3 classes: grade I (well differentiated), grade II (intermediately differentiated), and grade III (poorly differentiated) [33]. Grade I and II chondrosarcomas show a better outcome, whereas grade III chondrosarcomas are associated with a high recurrence rate and even metastases [34]. Chondrosarcomas stain positive for S-100 and vimentin but fail to express epithelial markers such as cytokeratin and epithelial membrane antigen (Fig. 1h, I, j), [35].

\section{Clinical Signs and Symptoms}

Patients with chordomas and chondrosarcomas usually present with nonspecific and sometimes confusing symptoms, which markedly delays the diagnosis until later stages of the disease [36-39]. The initial presentation of the tumors can significantly vary depending on the location, extension, and proximity of the lesion to critical structures. Besides headaches typically located in the occipital or retro-orbital region, the most commonly reported signs are neuro-ophthalmological [37-42]. The visual symptoms may include blurred vision or loss of vision, ptosis, and visual field defects related to cranial nerve palsies which could be explained by the location and growth pattern of the tumors [43-47]. It is not unusual for this kind of tumor to invade structures such as the cavernous sinus, the petroclival region, the cerebellopontine angle, the infratemporal fossa, the parapharyngeal space, and the temporal bone $[42,44,46]$. Other signs and symptoms that may present with clival lesions include hearing loss, facial paralysis or hypoesthesia, dysphonia, dysarthria, dysphagia, dyspnea, anosmia, and vertigo [44, 48, 49]. Involvement of the suprasellar space may lead to hypopituitarism and diabetes insipidus through damage of the pituitary gland or the stalk and visual impairment through damage to the optic apparatus, respectively $[50,51]$. Larger tumors may also compress the brainstem and cerebellum, causing gait disturbances, ataxia, dysmetria, and motor weakness (e.g., hemiparesis or tetraparesis) $[44,51,52]$. The nature of the tumor cannot be distinguished on the basis of the clinical presentation alone.

Skull Base Chordomas and Chondrosarcomas

\section{Endocrine Dysfunction}

Chordomas and chondrosarcomas can arise within the sellar/parasellar region but also extend into this region. In a large transsphenoidal surgical series about $10 \%$ of nonpituitary sellar lesions were found to be cartilaginous tumors. Chordomas were diagnosed more frequently than chondrosarcomas $[53,54]$. It is well known, that neither tumor entity secretes any bioactive compounds or hormones. Although there are a few published cases about endocrine abnormalities in patients presenting with these tumors, a significant endocrinopathy is highly unusual [53-59]. The most reported complaints were amenorrhea, galactorrhea, and male sexual dysfunction $[56,58-60]$. The severity of these symptoms was correlated with the level of hyperprolactinemia secondary to compression of the pituitary stalk. In rare cases, aggressive tumor growth may lead to partial or complete destruction of the pituitary gland, resulting in correspondingly variable degrees of hormonal deficiency $[57,61,62]$. Depending on the imaging peculiarities and presenting symptoms, a lack of systematic measurement of the preoperative hormonal status as part of the diagnostic workup could lead to the failed diagnosis of not clinically apparent hormonal deficiencies.

\section{Imaging}

Computed tomography (CT) and magnetic resonance imaging (MRI) are the preferred diagnostic tools for the initial evaluation of patients with suspicion of skull base neoplasms [63-65]. Preoperative sagittal and coronal multiplanar reconstructions are essential for evaluation of the detailed tumor's relationship to adjacent brain structures and hence planning of the optimal surgical treatment. In the follow-up, these planes are needed to detect treatment-related complications and tumor recurrences [66]. Since both tumors display an equally wide diversity in terms of their localization as well as the pattern and extent of invasive growth within the skull base, neither MRI nor CT can be useful for differentiating chordomas from chondrosarcomas preoperatively [6366].

\section{High-Resolution CT}

A high-resolution CT scan is sensitive enough to detect lesions of the skull base and should be performed with intravenous contrast and reviewed in bone and softtissue windows. Intracranial chordomas and chondrosar- 

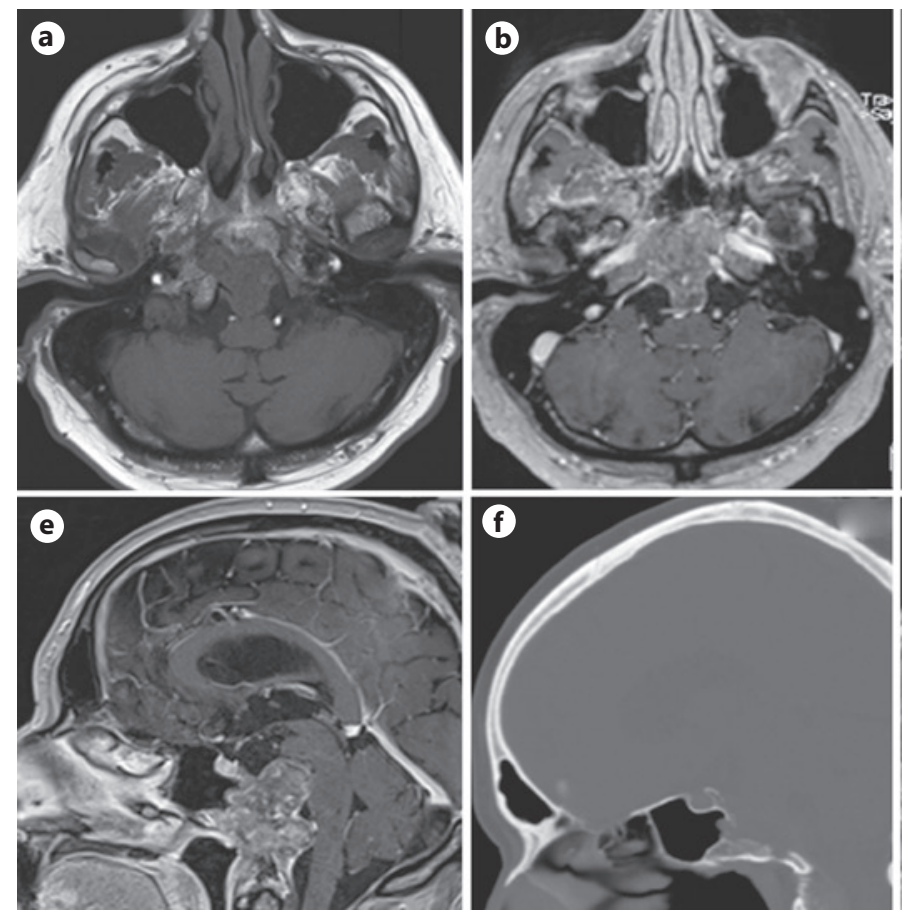
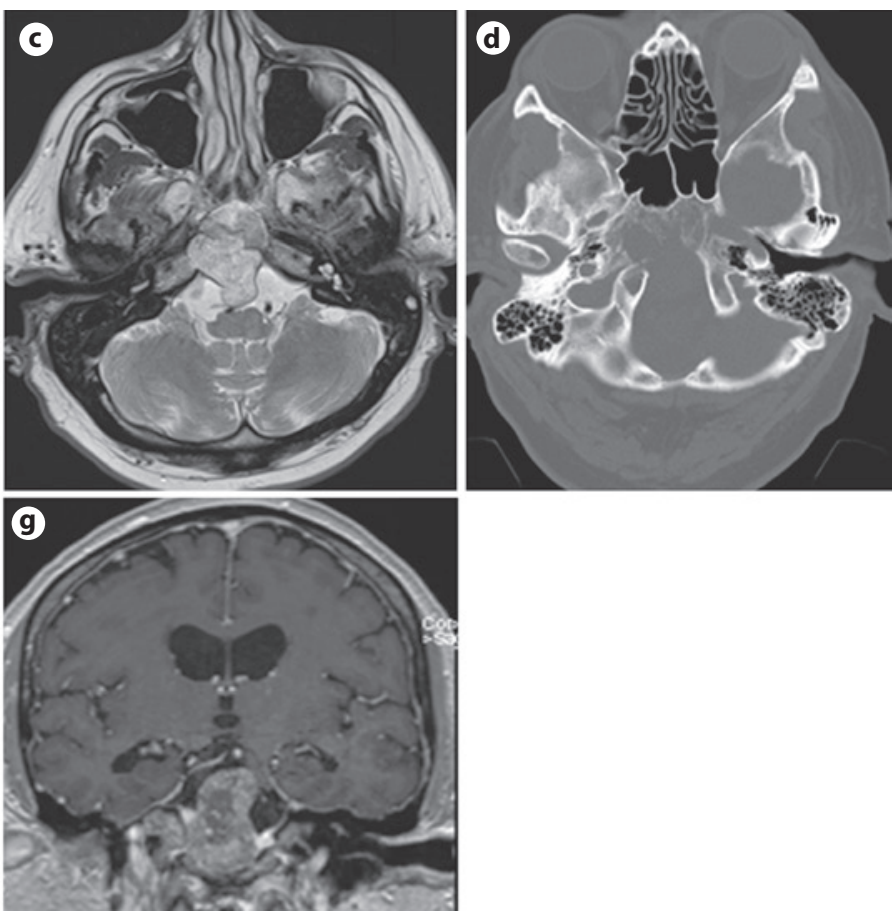

Fig. 2. MRI and CT scans of intracranial chordoma. Axial (a-c), sagittal (e), and coronal (g) T1-weighted and axial T2-weighted (c) MR images show a tumor with clival/retroclival extension. b, e, g Contrast-enhanced images. Axial (d) and sagittal (f) CT scans demonstrate involvement of the clivus.

comas are both delineated in CT scans, as are well-defined expansive tissue masses that arise from the clivus with associated osteolytic transformation with frequent expansion to the adjacent soft tissue $[67,68]$. The tumors are seen on noncontrast CT as isodense or slightly hypodense in comparison to normal brain tissue. Intratumoral calcifications are mostly found in chondrosarcomas and are hence suggestive of this diagnosis.

\section{Magnetic Resonance Imaging}

MRI provides optimal resolution and soft tissue contrast with exquisite anatomic details in the evaluation of intracranial lesions in comparison to CT scans $[69,70]$. The sagittal planar images are indispensable for identification of the posterior tumor margins, as well as their relation to the brainstem, and the coronal planar images are essential for identification of the lateral tumor margins and the tumor extension into the cavernous sinus. Intracranial chordomas and chondrosarcomas are characterized by an intermediate-to-low signal intensity on spin-echo T1weighted MR sequences and they are recognized within the high signal intensity of the clivus fat tissue. Small foci of hyperintensity recognized in T1-weighted sequences, appearing as bright spots and dark areas on gradient-weight- ed sequences, represent intratumoral hemorrhage or a mucus pool. Furthermore, the tumors show a high signal intensity on T2-weighted images. The sagittal and axial T1-weighted, postcontrast, fat-suppressed images also help to distinguish tumor from fat in the adjacent bone marrow spaces, since normal bone marrow in adults is characterized by a bright signal intensity on both T1weighted images and fast spin echo T2-weighted images $[71,72]$. Clival chordomas and chondrosarcomas may exhibit similar growth patterns by extending anteriorly, laterally, posteriorly, inferiorly, and superiorly with affection of the sellar/parasellar area, the middle cranial fossa, the prepontine cistern, and the foramen magnum (Fig. 2, 3). Nevertheless, a slight difference in predilection in terms of origin with chordomas tending to arise from the midline as opposed to more laterally for chondrosarcomas may be of use in the initial differential diagnosis on MRI.

\section{Treatment}

\section{Surgery}

Treatment of intracranial chordomas and chondrosarcomas still represents a big challenge despite advances in 

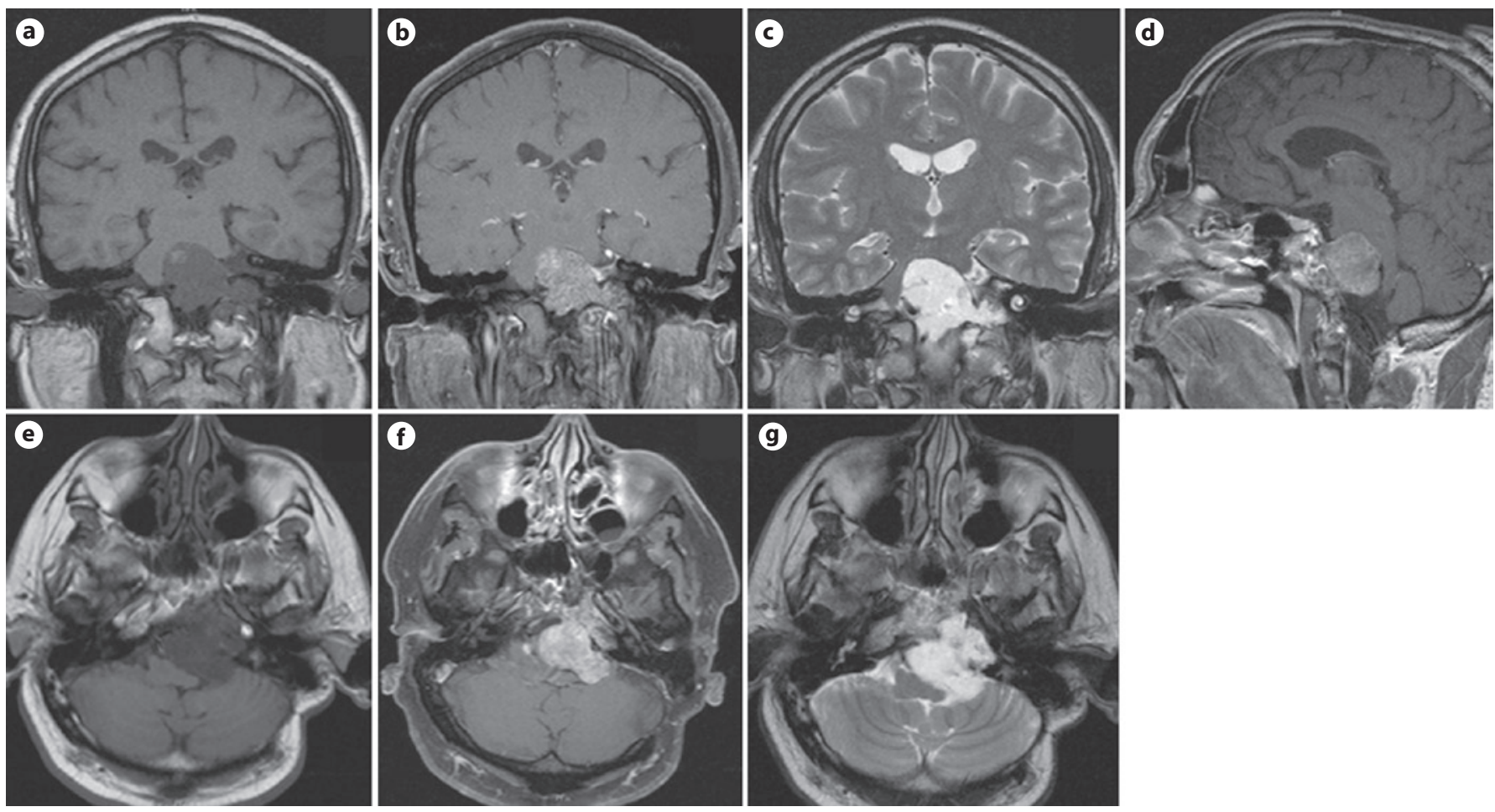

Fig. 3. MRI scans of intracranial chondrosarcoma. Coronal (a, b), sagittal (d), and axial (e, f) T1-weighted and coronal (c) and axial (g) T2-weighted MR images demonstrate a tumor with extension into the posterior fossa. b, e, $\mathbf{g}$ Contrast-enhanced images.

neurosurgical techniques [73-77]. The surgery philosophy is to remove as much tumor as possible and to preserve or improve the patient's status. Macroscopic complete resection with a negative surgical margin is usually impossible due to aggressive and infiltrative tumor growth pattern with involvement of the surrounding neurological structures [51, 73, 78-83]. Many surgical approaches have been described for the resection of skull base chordomas and chondrosarcomas. Taking into consideration the aggressive nature of these tumors and especially the patient's expectations, the best approaches or even multiple approaches must be selected on an individual basis. It is important to consider the common and serious complications that may occur following the resection of skull base lesions. Many authors report new cranial nerve deficits in up to $80 \%$ of the patients, which were frequently transient in the majority of cases. Other complications include cerebrospinal fluid leaks, meningitis, hearing loss, visual decline, and consequences of vascular injury [34, 84]. Neurosurgical approaches often used in the resection of intracranial chordomas and chondrosarcomas include the transsphenoidal, transbasal, cranioorbitozygomatic, transzygomatic extended middle fossa, transcondylar, and transmaxillary approaches [34, 7992]. Their applications are summarized as follows.

Transsphenoidal Approach. The transsphenoidal approach is a well-established method for the treatment of tumors limited to the upper clivus, the sellar und suprasellar regions, or the medial aspect of the cavernous sinus. This approach provides visualization to many intracranial anatomical structures (the internal carotid arteries, the pituitary gland, the infundibulum, the optic nerve and chiasm, the mammillary bodies, the basilar artery bifurcation, the hypothalamus etc.). This approach, mostly in an extended fashion, permits tumor resection with minimal displacement or distortion of surrounding tissue. The neurosurgeon can work effectively either above or below the optic chiasm, depending on its situation relative to the lesion. The transsphenoidal approach is the one most often used for the treatment of chordomas and chondrosarcomas in our institute.

Transbasal Approach. There are a number of modifications of the transbasal approach (e.g., uni- or bilateral orbital-cranial subfrontal transbasal, nasofrontal transbasal). It creates the possibility to reach the midline clivus, the medial cavernous sinus, the petrous apex, the occipital 
condyles, and the foramen magnum. However, this approach is a midline approach between the 2 optic nerves and cannot expose tumors located laterally to the internal carotid artery (ICA). The main disadvantage is the narrow and deep corridor between the optic nerves and the ICA.

Cranio-Orbitozygomatic Approach. This approach provides the shortest route with full exposure of lesions displacing the brain structures superiorly and laterally in the parasellar region. It gives a multidirectional view of the tumor and allows surgical dissection via multiple routes (subfrontal-transbasal, transsylvian, subtemporal, and infratemporal). Many authors have reported using this approach for tumors in the region of the upper clivus with extension lateral to the ICA and into the middle fossa, the petrous apex, and the infratemporal fossa.

Transzygomatic Extended Middle Fossa Approach. This approach has become useful in the treatment of lesions located in the infratemporal, sphenopalatine, and temporal fossae, the orbit, the petrous apex, the upper petroclival region, and the cavernous sinus. It creates a wider surgical corridor offering a direct view of the clivus and brainstem. Tumors extended in the sphenoid sinus can be removed through the Parkinson triangle between the first and second divisions of the fifth cranial nerve.

Transcondylar Approach. Many indications have been reported for the transcondylar approach. In selected cases, it allows approach to chordomas/chondrosarcoma in the region of the inferior clivus with lateral extension to the craniocervical junction or the upper cervical vertebrae. It requires extraperiosteal management of the vertebral artery. This approach can be combined with a transtemporal approach superiorly and a transcervical approach inferiorly. However, the surgery can cause cerebellar damage, vertebral artery injury, or occipito-cervical instability, where extensive condyle resection may even require future occipito-cervical fusion.

Transmaxillary Approach. This technique enables tumor resection located in the clivus area with extension into the nasopharynx or craniocervical junction, inferior to the anterior cranial fossa, superior to the $\mathrm{C} 2-\mathrm{C} 3$ interspace, and medial to the pterygoid plate. The maxillary osteotomy provides a direct view of the clivus region, the posterior nasooropharynx, and the cervical spine. This approach is associated in appropriately selected patients with limited morbidity and mortality. Procedurally related complications include damage to neurovascular structures along the paramedian skull base, including maxillary, mandibular, and vidian neurovascular bundles. The risk of aseptic bone necrosis is increased with multisegmented osteotomies and intraoperative hypotension.

\section{Radiotherapy}

The recent literature supports the concept of a combination treatment for chordomas and chondrosarcomas consisting of surgical resection with maximal excision followed by adjuvant radiotherapy [84, 93-97]. It is believed that radiation therapy leads to clearance of the tumor bed from invisible, microscopic tumor nests. The most common adjuvant treatment methods for chordomas and chondrosarcomas include high-dose radiotherapy with proton beam radiation and radiosurgery using a gamma knife and a CyberKnife [98-102]. However, there are no published studies directly comparing these forms of radiation therapy [103]. Retrospective studies have shown a longer local progression-free time following adjuvant radiotherapy. Conventional radiotherapy does not appear to increase the survival duration. The 5-year recurrence-free survival for cranial base chordomas after proton-based therapy ranges between 59 and $73 \%$ [94, $100,104]$. In contrast, skull base chondrosarcomas after the same proton-based therapy are characterized by a disease-specific 5-year survival rate of about 99\% [102]. Adjuvant radiotherapy is not indicated for chondrosarcomas of WHO grade I and II in case of complete resection, as opposed to chordomas where this is universally advocated.

\section{Chemotherapy}

Traditionally, chordomas and chondrosarcomas are not sensitive to chemotherapy $[105,106]$ and there are no drugs approved for their treatment [106-108]. Dysregulation of different signaling pathways has been found in the development of chordomas and chondrosarcomas [109-119]. Agents that interrupt these signaling pathways could become attractive targets for anticancer therapy. Tyrosine kinase inhibitors (TKI) showed activity against chordomas as a result of targeted inhibition of several intersecting molecular pathways [120]. In a small number of patients treated with the TKI sunitinib, stable disease for at least 16 weeks was achieved [121]. Other studies have demonstrated that TKI, such as imatinib mesylate and erlonitib, and epidermal growth factor receptor inhibitors such as cetuximab and gefitinib, have a beneficial effect on the treatment of advanced or metastatic chordomas [122-124]. TKI, mTOR, hedgehog, and AKT inhibitors have also been tested in clinical studies for chondrosarcoma patients [115-119]. Unfortunately, most of them have failed to demonstrate a clinical benefit in terms of disease progression or outcomes. However, all clinical reports have been limited by a small patient numbers and short fol- 
low-ups. Finally, the published studies are clinical phase I/II studies, rendering it difficult to arrive at any conclusions.

It is of interest to note that immunotherapy based on enhancement of the immune system to eliminate cancer cells has developed into a promising modality in cancer therapy [125-127]. As in the case of other human cancers, it has recently been demonstrated that some fractions of chordoma cells escape immune modulated destruction by upregulating the programmed death-1 receptor (PD-1) and programmed cell death ligand 1 (PD-L1) [128-130]. Many checkpoint inhibitor (ICI) antibodies blocking the PD-1/PD-L1 pathways have been developed and introduced into clinical practice [131, 132]. Migliorini et al. [133] have published anecdotal cases of clinical responses to immunotherapy with ICI in relapsing chordomas. Although there are currently several clinical studies on chordomas and ICI (for details, please see https://clinicaltrials.gov), it remains too early to speculate on whether adding ICI antibodies to existing treatment protocols of chordomas could improve the outcome.

\section{Prognosis and Outcome}

There are no reliable markers for the prognosis of skull base chondrosarcomas and chordomas known to date. However, Weber et al. [134] identified histology, gross tumor volume, and brain compression as independent prognostic factors for local control and overall survival (OS) based on multivariate analysis. On the other hand, several authors have considered the prognosis to be based on multiple factors [3-5, 8, 42, 78, 79, 82, 84, 92-94]. Dedifferentiated chordomas exhibit a particularly poor prognosis with an aggressive clinical course. This subtype has a 60\% 3-year OS compared to an 89.4\% 3-year OS for classical chordomas [10,15, 16, 79]. Poorly differentiated or grade III chondrosarcomas show aggressive behavior and are associated with the lowest survival rates [10]. Tumor volume has been incorporated in the TNM staging system and can be considered as a potential prognostic factor. Kamrin et al. [135] reported a mean survival time for untreated chordoma patients ranging from 6 to 24 months. According to published data, the median OS of patients with chordomas after surgery and radiation was 6.29 years [3], the 5-year progression-free survival varied from 45 to $56 \%[3,8,9]$ and 10 -year OS rates ranged from 32 to $60 \%$ [16]. Metastases from chordomas from all anatomic sites have been estimated to vary from 9 to $41 \%$ [ 78 ,
136-139]. In a systematic review of 560 patients with intracranial chondrosarcomas, the calculated 5-year mortality was $11.5 \%$, with a median survival time of 24 months [10]. The Surveillance, Epidemiology, and End Results program of the National Cancer Institute shows an OS of $65 \%$ for chordomas and $82 \%$ for chondrosarcomas at 5 years, as well as rates of 32 and $50 \%$ at 10 years, respectively [140].

\section{Conclusion}

Skull base chordomas and chondrosarcomas are local invasive and destructive growing tumors with a high locoregional recurrence rate and rare distant metastases. The patients often have nonspecific and confusing symptoms independently of the tumor subtype. CT and MRI still represent equally valuable diagnostic tools for the initial evaluation of patients with a suspected brain disease. Preoperative differentiation between chordomas and chondrosarcomas based on the clinical presentation and clinical and instrument-based diagnostics alone is impossible. The treatment philosophy for both intracranial tumor entities is to maximize tumor resection, minimize morbidity, and preserve function. The appropriate approaches or even multiple approaches must be determined on a case-by-case basis. Surgery should be followed by adjuvant radiotherapy to improve the local progression-free time, where proton-beam therapy has been shown to be more profitable than conventional radiotherapy. To date, there are no drug agents approved for the treatment of chordomas and chondrosarcomas. In recapitulation, from our personal point of view, intracranial skull base chordomas and chondrosarcomas should be subjected to the maximum possible cytoreduction via an appropriate approach without deterioration of the general condition and without incurring in neurological deficits followed by radiotherapy in the form of proton beam therapy.

\section{Statement of Ethics}

The authors have no ethical conflicts to disclose.

\section{Conflict of Interest Statement}

The authors have no conflict of interests to declare 


\section{Funding Sources}

There was no funding support for this article.

\section{Author Contributions}

Conception, design, and writing of this paper: N.K. and M.B. Redaction: S.-M.S., R.C., T.G., and T.M.K. All of the authors approved the final submitted version of this work.

\section{References}

1 Mizerny BR, Kost KM. Chordoma of the cranial base: the McGill experience. J Otolaryngol. 1995 Feb;24(1):14-9.

2 Lee SY, Lim YC, Song MH, Seok JY, Lee WS, Choi EC. Chondrosarcoma of the head and neck. Yonsei Med J. 2005 Apr;46(2):228-32.

3 McMaster ML, Goldstein AM, Bromley CM, Ishibe N, Parry DM. Chordoma: incidence and survival patterns in the United States, 1973-1995. Cancer Causes Control. 2001 Jan; 12(1):1-11.

4 Eriksson B, Gunterberg B, Kindblom LG. Chordoma. A clinicopathologic and prognostic study of a Swedish national series. Acta Orthop Scand. 1981 Feb;52(1):49-58.

5 O'Neill P, Bell BA, Miller JD, Jacobson I, Guthrie W. Fifty years of experience with chordomas in southeast Scotland. Neurosurgery. 1985 Feb;16(2):166-70.

6 Hoch BL, Nielsen GP, Liebsch NJ, Rosenberg AE. Base of skull chordomas in children and adolescents: a clinicopathologic study of 73 cases. Am J Surg Pathol. 2006 Jul;30(7):811-8.

7 Cianfriglia F, Pompili A, Occhipinti E. Intracranial malignant cartilaginous tumours. Report of two cases and review of literature. Acta Neurochir (Wien). 1978;45(1-2):163-75.

8 Harvey SA, Wiet RJ, Kazan R. Chondrosarcoma of the jugular foramen. Am J Otol. 1994 Mar;15(2):257-63.

9 Donaldson DR, Myers LL, Diaz-Ordaz E, Grand W, Paterson J, Wax MK. Pathologic quiz case 2: chondrosarcoma of the jugular foramen. Arch Otolaryngol Head Neck Surg. 1999 Feb;125(2):229.

10 Bloch OG, Jian BJ, Yang I, Han SJ, Aranda D, Ahn BJ, et al. A systematic review of intracranial chondrosarcoma and survival. J Clin Neurosci. 2009 Dec;16(12):1547-51.

11 Virchow RL. Untersuchungen über die Entwickelung des Schädelgrundes im gesunden und krankhaften Zustande: und über den Einfluss derselben auf Schädelform, Gesichtsbildung und Gehirnbau. Berlin: G Reimer; 1857.

12 Williams LW. The later development of the notochord in mammals. Am J Anat. 1908; 8(1):251-84.

13 Chugh R, Tawbi H, Lucas DR, Biermann JS, Schuetze SM, Baker LH. Chordoma: the nonsarcoma primary bone tumor. Oncologist. 2007 Nov;12(11):1344-50.

14 Ouyang T, Zhang N, Zhang Y, Jiao J, Ren J, Huang T, et al. Clinical characteristics, immunohistochemistry, and outcomes of $77 \mathrm{pa}-$ tients with skull base chordomas. World Neurosurg. 2014 May-Jun;81(5-6):790-7.
15 Menezes AH. Clival and craniovertebral junction chordomas. World Neurosurg. 2014 May-Jun;81(5-6):690-2.

16 Casali PG, Stacchiotti S, Sangalli C, Olmi P, Gronchi A. Chordoma. Curr Opin Oncol. 2007 Jul;19(4):367-70.

17 Abenoza P, Sibley RK. Chordoma: an immunohistologic study. Hum Pathol. 1986 Jul; 17(7):744-7.

18 Meis JM, Giraldo AA. Chordoma. An immunohistochemical study of 20 cases. Arch Pathol Lab Med. 1988 May;112(5):553-6.

19 Wick MR, Burgess JH, Manivel JC. A reassessment of "chordoid sarcoma". Ultrastructural and immunohistochemical comparison with chordoma and skeletal myxoid chondrosarcoma. Mod Pathol. 1988 Nov;1(6):433-43.

20 Walker WP, Landas SK, Bromley CM, Sturm MT. Immunohistochemical distinction of classic and chondroid chordomas. Mod Pathol. 1991 Sep;4(5):661-6.

21 Vujovic S, Henderson S, Presneau N, Odell E, Jacques TS, Tirabosco R, et al. Brachyury, a crucial regulator of notochordal development, is a novel biomarker for chordomas. J Pathol. 2006 Jun;209(2):157-65.

22 Romeo S, Hogendoorn PC. Brachyury and chordoma: the chondroid-chordoid dilemma resolved? J Pathol. 2006 Jun;209(2):143-6.

23 Zhang L, Guo S, Schwab JH, Nielsen GP, Choy E, Ye S, et al. Tissue microarray immunohistochemical detection of brachyury is not a prognostic indicator in chordoma. PLoS One. 2013 Sep;8(9):e75851.

24 Miettinen M, Wang Z, Lasota J, Heery C, Schlom J, Palena C. Nuclear brachyury expression is consistent in chordoma, common in germ cell tumors and small cell carcinomas, and rare in other carcinomas and sarcomas: an immunohistochemical study of 5229 cases. Am J Surg Pathol. 2015 Oct;39(10):1305-12.

25 Barresi V, Ieni A, Branca G, Tuccari G. Brachyury: a diagnostic marker for the differential diagnosis of chordoma and hemangioblastoma versus neoplastic histological mimickers. Dis Markers. 2014;2014:514753.

26 Jambhekar NA, Rekhi B, Thorat K, Dikshit R, Agrawal M, Puri A. Revisiting chordoma with brachyury, a "new age" marker: analysis of a validation study on 51 cases. Arch Pathol Lab Med. 2010 Aug;134(8):1181-7.

27 Oakley GJ, Fuhrer K, Seethala RR. Brachyury, SOX-9, and podoplanin, new markers in the skull base chordoma vs chondrosarcoma differential: a tissue microarray-based comparative analysis. Mod Pathol. 2008 Dec;21(12): 1461-9.
28 Mott FW. Chondrosarcoma springing from the sella turcica. Arch Neurol Psychiatry. 1899;1:432-3.

29 Varma DG, Ayala AG, Carrasco CH, Guo SQ, Kumar R, Edeiken J. Chondrosarcoma: MR imaging with pathologic correlation. Radiographics. 1992 Jul;12(4):687-704.

30 Suster D, Hung YP, Nielsen GP. Differential diagnosis of cartilaginous lesions of bone. Arch Pathol Lab Med. 2020 Jan;144(1):71-82.

31 Evans HL, Ayala AG, Romsdahl MM. Prognostic factors in chondrosarcoma of bone: a clinicopathologic analysis with emphasis on histologic grading. Cancer. 1977 Aug;40(2): 818-31.

32 Fletcher $\mathrm{CD}$. The evolving classification of soft tissue tumours - an update based on the new 2013 WHO classification. Histopathology. 2014 Jan;64(1):2-11.

33 Hogendoorn PC, Bovee JV, Nielsen GP. Chondrosarcoma (grades I-III), including primary and secondary variants and periosteal chondrosarcoma. In: Fletcher CD, Bridge JA, Hogendoorn PC, Mertens F, editors. WHO classification of tumours of soft tissue and bone. 4th ed. Lyon: IARC Press; 2013. pp. 264-8.

34 Gay E, Sekhar LN, Rubinstein E, Wright DC, Sen C, Janecka IP, et al. Chordomas and chondrosarcomas of the cranial base: results and follow-up of 60 patients. Neurosurgery. 1995 May;36(5):887-96.

35 Rosenberg AE, Brown GA, Bhan AK, Lee JM. Chondroid chordoma-a variant of chordoma. A morphologic and immunohistochemical study. Am J Clin Pathol. 1994 Jan;101(1): $36-41$.

36 Lim GH. Clivus chordoma with unusual bone sclerosis and brainstem invasion. A case report with review of the radiology of cranial chordomas. Australas Radiol. 1975 Sep;19(3): 242-50.

37 Roberti F, Sekhar LN, Jones RV, Wright DC. Intradural cranial chordoma: a rare presentation of an uncommon tumor. Surgical experience and review of the literature. J Neurosurg. 2007 Feb;106(2):270-4.

38 Neff B, Sataloff RT, Storey L, Hawkshaw M, Spiegel JR. Chondrosarcoma of the skull base. Laryngoscope. 2002 Jan;112(1):134-9.

39 Lustig LR, Sciubba J, Holliday MJ. Chondrosarcomas of the skull base and temporal bone. J Laryngol Otol. 2007 Aug;121(8):725-35.

40 Volpe NJ, Liebsch NJ, Munzenrider JE, Lessell $\mathrm{S}$. Neuro-ophthalmologic findings in chordo$\mathrm{ma}$ and chondrosarcoma of the skull base. Am J Ophthalmol. 1993 Jan;115(1):97-104. 
41 Bagan SM, Hollenhorst RW. Ocular manifestations of intracranial chordomas. Trans Am Ophthalmol Soc. 1980;78:148-55.

42 Lanzino G, Sekhar LN, Hirsch WL, Sen CN Pomonis S, Snyderman CH. Chordomas and chondrosarcomas involving the cavernous sinus: review of surgical treatment and outcome in 31 patients. Surg Neurol. 1993 Nov; 40(5):359-71.

43 Masui K, Kawai S, Yonezawa T, Fujimoto K, Nishi N. Intradural retroclival chordoma without bone involvement - case report. Neurol Med Chir (Tokyo). 2006 Nov;46(11):552-

44 Korinth M, Schönrock L, Mayfrank L, Gilsbach JM. Primary intradural pontocerebellar chordoma metastasizing in the subarachnoid spinal canal. Zentralbl Neurochir. 1999;60(3): 146-50.

45 Mapstone TB, Wongmongkolrit T, Roessman $\mathrm{U}$, Ratcheson RA. Intradural chondroma: a case report and review of the literature. Neurosurgery. $1983 \mathrm{Jan} ; 12(1): 111-4$.

46 Wolfe JT 3rd, Scheithauer BW. "Intradural chordoma" or "giant ecchordosis physaliphora"? Report of two cases. Clin Neuropathol. 1987 May-Jun;6(3):98-103.

47 Tashiro T, Fukuda T, Inoue Y, Nemoto Y, Shakudo M, Katsuyama J, et al. Intradural chordoma: case report and review of the literature. Neuroradiology. 1994 May;36(4): 313-5.

48 Hardie RC. Magnetic resonance appearance of a rare intradural chordoma. Wis Med J. 1992 Nov;91(11):627-8.

49 Korten AG, ter Berg HJ, Spincemaille GH, van der Laan RT, Van de Wel AM. Intracranial chondrosarcoma: review of the literature and report of 15 cases. J Neurol Neurosurg Psychiatry. 1998 Jul;65(1):88-92.

50 Mathews W, Wilson CB. Ectopic intrasellar chordoma. Case report. J Neurosurg. 1974 Feb;40(2):260-3.

51 Zhang Z, Pang LJ, Wang N, Li Z, Cao YW, Hu $\mathrm{WH}$, et al. Low-grade chondrosarcoma in the sellar area: case report and literature review. OncoTargets Ther. 2019 Dec;12:10763-70.

52 Asioli S, Zoli M, Guaraldi F, Sollini G, Bacci A, Gibertoni D, et al. Peculiar pathological, radiological and clinical features of skull-base de-differentiated chordomas. Results from a referral centre case-series and literature review. Histopathology. 2020 Apr;76(5):731-9.

53 Freda PU, Wardlaw SL, Post KD. Unusual causes of sellar/parasellar masses in a large transsphenoidal surgical series. J Clin Endocrinol Metab. 1996 Oct;81(10):3455-9.

54 Freda PU, Post KD. Differential diagnosis of sellar masses. Endocrinol Metab Clin North Am. 1999 Mar;28(1):81-117.

55 Thodou E, Kontogeorgos G, Scheithauer BW, Lekka I, Tzanis S, Mariatos P, et al. Intrasellar chordomas mimicking pituitary adenoma. J Neurosurg. 2000 Jun;92(6):976-82.

56 Allan CA, Kaltsas G, Evanson J, Geddes J, Lowe DG, Plowman PN, et al. Pituitary chondrosarcoma: an unusual cause of a sellar mass presenting as a pituitary adenoma. J Clin Endocrinol Metab. 2001 Jan;86(1):386-91.

57 Hirosawa RM, Santos AB, França MM, Fabris VE, Castro AV, Zanini MA, et al. Intrasellar chondroid chordoma: a case report. ISRN Endocrinol. 2011;2011:259392.

58 Hattori Y, Tahara S, Nakakuki T, Takei M, Ishii Y, Teramoto A, et al. Sellar chondroma with endocrine dysfunction that resolved after surgery: case report. J Nippon Med Sch. 2015;82(3):146-50

59 Cao J, Li G, Sun Y, Hong X, Huang H. Sellar chondrosarcoma presenting with amenorrhea: A case report. Medicine (Baltimore). 2018 Jul;97(27):e11274.

60 Glezer A, Paraiba DB, Bronstein MD. Rare sellar lesions. Endocrinol Metab Clin North Am. 2008 Mar;37(1):195-211.

61 Abele TA, Yetkin ZF, Raisanen JM, Mickey BE, Mendelsohn DB. Non-pituitary origin sellar tumours mimicking pituitary macroadenomas. Clin Radiol. 2012 Aug;67(8):821-7.

62 Kagawa T, Takamura M, Moritake K, Tsutsumi A, Yamasaki T. A case of sellar chordoma mimicking a non-functioning pituitary adenoma with survival of more than 10 years. Noshuyo Byori. 1993;10(2):103-6.

63 Oot RF, Melville GE, New PF, Austin-Seymour M, Munzenrider J, Pile-Spellman J, et al. The role of MR and CT in evaluating clival chordomas and chondrosarcomas. AJR Am J Roentgenol. 1988 Sep;151(3):567-75.

64 Müller U, Kubik-Huch RA, Ares C, Hug EB, Löw R, Valavanis A, et al. Is there a role for conventional MRI and MR diffusion-weighted imaging for distinction of skull base chordoma and chondrosarcoma? Acta Radiol. 2016 Feb;57(2):225-32.

65 Welzel T, Meyerhof E, Uhl M, Huang K, von Deimling A, Herfarth K, et al. Diagnostic accuracy of DW MR imaging in the differentiation of chordomas and chondrosarcomas of the skull base: a 3.0-T MRI study of 105 cases. Eur J Radiol. 2018 Aug;105:119-24.

66 Doucet V, Peretti-Viton P, Figarella-Branger D, Manera L, Salamon G. MRI of intracranial chordomas. Extent of tumour and contrast enhancement: criteria for differential diagnosis. Neuroradiology. 1997 Aug; 39(8):571-6.

67 Meyer JE, Oot RF, Lindfors KK. CT appearance of clival chordomas. J Comput Assist Tomogr. 1986 Jan-Feb;10(1):34-8.

68 Schamschula RG, Soo MY. Clival chordomas. Australas Radiol. 1993 Aug;37(3):259-64.

69 Sze G, Uichanco LS 3rd, Brant-Zawadzki MN, Davis RL, Gutin PH, Wilson CB, et al. Chordomas: MR imaging. Radiology. 1988 Jan; 166(1 Pt 1):187-91.

70 Meyers SP, Hirsch WL Jr, Curtin HD, Barnes L, Sekhar LN, Sen C. Chordomas of the skull base: MR features. AJNR Am J Neuroradiol. 1992 Nov-Dec;13(6):1627-36.

71 Erdem E, Angtuaco EC, Van Hemert R, Park JS, Al-Mefty O. Comprehensive review of intracranial chordoma. Radiographics. 2003 Jul-Aug;23(4):995-1009.
72 Yeom KW, Lober RM, Mobley BC, Harsh G, Vogel H, Allagio R, et al. Diffusion-weighted MRI: distinction of skull base chordoma from chondrosarcoma. AJNR Am J Neuroradiol. 2013 May;34(5):1056-61.

73 al-Mefty O, Borba LA. Skull base chordomas: a management challenge. J Neurosurg. 1997 Feb;86(2):182-9.

74 Abdulrauf SI. Decision-making process for the treatment of intracranial chordomas. World Neurosurg. 2014 Nov;82(5):612-3.

75 Guinto G, Guinto-Nishimura Y. Clivus chordomas: role of surgery. World Neurosurg. 2014 May-Jun;81(5-6):688-9.

76 Tomasello F, Conti A. Chordomas: what's new? World Neurosurg. 2014 Nov;82(5):610-1.

77 Al-Mefty O. Chordoma. Acta Neurochir (Wien). 2017 Oct;159(10):1869-71.

78 Tzortzidis F, Elahi F, Wright D, Natarajan SK, Sekhar LN. Patient outcome at long-term follow-up after aggressive microsurgical resection of cranial base chordomas. Neurosurgery. 2006 Aug;59(2):230-7.

79 Labidi M, Watanabe K, Bouazza S, Bresson D, Bernat AL, George B, et al. Clivus chordomas: a systematic review and meta-analysis of contemporary surgical management. J Neurosurg Sci. 2016 Dec;60(4):476-84.

80 Stippler M, Gardner PA, Snyderman CH, Carrau RL, Prevedello DM, Kassam AB. Endoscopic endonasal approach for clival chordomas. Neurosurgery. 2009 Feb;64(2):26877.

81 Jho HD. Endoscopic transsphenoidal surgery. J Neurooncol. 2001 Sep;54(2):187-95.

82 Sen C, Triana AI, Berglind N, Godbold J, Shrivastava RK. Clival chordomas: clinical management, results, and complications in 71 patients. J Neurosurg. 2010 Nov; 113(5): 1059-71.

83 Tan NC, Naidoo Y, Oue S, Alexander H, Robinson S, Wickremesekera A, et al. Endoscopic surgery of skull base chordomas. J Neurol Surg B Skull Base. 2012 Dec;73(6):379-86.

84 Samii A, Gerganov VM, Herold C, Hayashi N, Naka T, Mirzayan MJ, et al. Chordomas of the skull base: surgical management and outcome. J Neurosurg. 2007 Aug;107(2):319-24.

85 Makhdoomi R, Ramzan A, Khursheed N, Bhat S, Baba K, Mohsin R, et al. Clinicopathological characteristics of chordoma: an institutional experience and a review of the literature. Turk Neurosurg. 2013;23(6):700-6.

86 Singh H, Harrop J, Schiffmacher P, Rosen M, Evans J. Ventral surgical approaches to craniovertebral junction chordomas. Neurosurgery. 2010 Mar;66(3 Suppl):96-103.

87 Maira G, Pallini R, Anile C, Fernandez E, Salvinelli F, La Rocca LM, et al. Surgical treatment of clival chordomas: the transsphenoidal approach revisited. J Neurosurg. 1996 Nov;85(5):784-92.

88 Sekhar LN, Nanda A, Sen CN, Snyderman $\mathrm{CN}$, Janecka IP. The extended frontal approach to tumors of the anterior, middle, and posterior skull base. J Neurosurg. 1992 Feb; 76(2):198-206 
89 Derome PJ. The transbasal approach to tumors invading the skullbase. In: Schmidek $\mathrm{HH}$, Sweet HW, editors. Operative neurosurgical techniques: indications, methods, and results. Philadelphia: Saunders; 1993. pp. $427-41$.

90 Menezes AH, Gantz BJ, Traynelis VC, McCulloch TM. Cranial base chordomas. Clin Neurosurg. 1997;44:491-509.

91 Dehdashti AR, Karabatsou K, Ganna A, Witterick I, Gentili F. Expanded endoscopic endonasal approach for treatment of clival chordomas: early results in 12 patients. Neurosurgery. 2008 Aug;63(2):299-307.

92 Fraser JF, Nyquist GG, Moore N, Anand VK, Schwartz TH. Endoscopic endonasal transclival resection of chordomas: operative technique, clinical outcome, and review of the literature. J Neurosurg. 2010 May; 112(5):1061-9.

93 Colli BO, Al-Mefty O. Chordomas of the skull base: follow-up review and prognostic factors. Neurosurg Focus. 2001 Mar;10(3): E1.

94 Castro JR, Linstadt DE, Bahary JP, Petti PL, Daftari I, Collier JM, et al. Experience in charged particle irradiation of tumors of the skull base: 1977-1992. Int J Radiat Oncol Biol Phys. 1994 Jul;29(4):647-55.

95 Hug EB, Fitzek MM, Liebsch NJ, Munzenrider JE. Locally challenging osteo- and chondrogenic tumors of the axial skeleton: results of combined proton and photon radiation therapy using three-dimensional treatment planning. Int J Radiat Oncol Biol Phys. 1995 Feb;31(3):467-76.

96 Brackmann DE, Teufert KB. Chondrosarcoma of the skull base: long-term follow-up. Otol Neurotol. 2006 Oct;27(7):981-91.

97 Bloch O, Parsa AT. Skull base chondrosarcoma: evidence-based treatment paradigms. Neurosurg Clin N Am. 2013 Jan;24(1):89-96.

98 Pearlman AW, Friedman M. Radical radiation therapy of chordoma. Am J Roentgenol Radium Ther Nucl Med. 1970 Feb;108(2): 332-41.

99 Muthukumar N, Kondziolka D, Lunsford LD, Flickinger JC. Stereotactic radiosurgery for chordoma and chondrosarcoma: further experiences. Int J Radiat Oncol Biol Phys. 1998 May;41(2):387-92.

100 Munzenrider JE, Liebsch NJ. Proton therapy for tumors of the skull base. Strahlenther Onkol. 1999 Jun;175(S2 Suppl 2):57-63.

101 Noël G, Feuvret L, Calugaru V, Dhermain F, Mammar H, Haie-Méder C, et al. Chordomas of the base of the skull and upper cervical spine. One hundred patients irradiated by a $3 \mathrm{D}$ conformal technique combining photon and proton beams. Acta Oncol. 2005;44(7):700-8

102 Rosenberg AE, Nielsen GP, Keel SB, Renard LG, Fitzek MM, Munzenrider JE, et al. Chondrosarcoma of the base of the skull: a clinicopathologic study of 200 cases with emphasis on its distinction from chordoma. Am J Surg Pathol. 1999 Nov;23(11):1370-8.
103 Amichetti M, Cianchetti M, Amelio D, Enrici RM, Minniti G. Proton therapy in chordoma of the base of the skull: a systematic review. Neurosurg Rev. 2009 Oct;32(4):40316.

104 Hug EB, Loredo LN, Slater JD, DeVries A, Grove RI, Schaefer RA, et al. Proton radiation therapy for chordomas and chondrosarcomas of the skull base. J Neurosurg. 1999 Sep;91(3):432-9.

105 Diaz RJ, Cusimano MD. The biological basis for modern treatment of chordoma. J Neurooncol. 2011 Sep;104(2):411-22.

106 Italiano A, Mir O, Cioffi A, Palmerini E, Piperno-Neumann S, Perrin C, et al. Advanced chondrosarcomas: role of chemotherapy and survival. Ann Oncol. 2013 Nov; 24(11):2916-22.

107 Stacchiotti S, Sommer J; Chordoma Global Consensus Group. Building a global consensus approach to chordoma: a position paper from the medical and patient community. Lancet Oncol. 2015 Feb;16(2):e71-83.

108 Stacchiotti S, Gronchi A, Fossati P, Akiyama T, Alapetite C, Baumann M, et al. Best practices for the management of local-regional recurrent chordoma: a position paper by the Chordoma Global Consensus Group. Ann Oncol. 2017 Jun;28(6):1230-42.

109 Xia M, Huang R, Sakamuru S, Alcorta D, Cho $\mathrm{MH}$, Lee DH, et al. Identification of repurposed small molecule drugs for chordoma therapy. Cancer Biol Ther. 2013 Jul; 14(7):638-47.

110 Weinberger PM, Yu Z, Kowalski D, Joe J, Manger P, Psyrri A, et al. Differential expression of epidermal growth factor receptor, cMet, and HER2/neu in chordoma compared with 17 other malignancies. Arch Otolaryngol Head Neck Surg. 2005 Aug;131(8):70711.

111 Tamborini E, Miselli F, Negri T, Lagonigro MS, Staurengo S, Dagrada GP, et al. Molecular and biochemical analyses of platelet-derived growth factor receptor (PDGFR) B, PDGFRA, and KIT receptors in chordomas. Clin Cancer Res. 2006 Dec; 12(23):6920-8.

112 Tatman PD, Osbun J, Yakkioui Y, Kaur S, Parada C, Busald T, et al. Kinase activity in recurring primary skull base chordomas and chondrosarcomas: identification of novel pathways of oncogenesis and otential drug targets. World Neurosurg. 2017 Nov;107: $75-81$.

113 Presneau N, Shalaby A, Idowu B, Gikas P, Cannon SR, Gout I, et al. Potential therapeutic targets for chordoma: PI3K/AKT/TSC1/ TSC2/mTOR pathway. Br J Cancer. 2009 May;100(9):1406-14.

114 Akhavan-Sigari R, Gaab MR, Rohde V, Brandis A, Tezval H, Abili M, et al. Expression of vascular endothelial growth factor receptor 2 (VEGFR-2), inducible nitric oxide synthase (iNOS), and Ki-M1P in skull base chordoma: a series of 145 tumors. Neurosurg Rev. 2014 Jan;37(1):79-88.
115 Grignani G, Palmerini E, Stacchiotti S, Boglione A, Ferraresi V, Frustaci S, et al. A phase 2 trial of imatinib mesylate in patients with recurrent nonresectable chondrosarcomas expressing platelet-derived growth factor receptor- $\alpha$ or $-\beta$ : An Italian Sarcoma Group study. Cancer. 2011 Feb;117(4):82631.

116 Schwartz GK, Tap WD, Qin LX, Livingston MB, Undevia SD, Chmielowski B, et al. Cixutumumab and temsirolimus for patients with bone and soft-tissue sarcoma: a multicentre, open-label, phase 2 trial. Lancet Oncol. 2013 Apr;14(4):371-82.

117 Thornton KA, Chen AR, Trucco MM, Shah P, Wilky BA, Gul N, et al. A dose-finding study of temsirolimus and liposomal doxorubicin for patients with recurrent and refractory bone and soft tissue sarcoma. Int J Cancer. 2013 Aug;133(4):997-1005.

118 Italiano A, Le Cesne A, Bellera C, PipernoNeumann S, Duffaud F, Penel N, et al. GDC0449 in patients with advanced chondrosarcomas: a French sarcoma group/US and French National Cancer Institute single-arm phase II collaborative study. Ann Oncol. 2013 Nov;24(11):2922-6.

119 Speetjens FM, de Jong Y, Gelderblom H, Bovée JV. Molecular oncogenesis of chondrosarcoma: impact for targeted treatment. Curr Opin Oncol. 2016 Jul;28(4):314-22.

120 Stacchiotti S, Morosi C, Lo Vullo S, Casale A, Palassini E, Frezza AM, et al. Imatinib and everolimus in patients with progressing advanced chordoma: a phase 2 clinical study. Cancer. 2018 Oct;124(20):4056-63.

121 Lipplaa A, Dijkstra S, Gelderblom H. Efficacy of pazopanib and sunitinib in advanced axial chordoma: a single reference centre case series. Clin Sarcoma Res. 2016 Nov; 6(1):19.

122 Singhal N, Kotasek D, Parnis FX. Response to erlotinib in a patient with treatment refractory chordoma. Anticancer Drugs. 2009 Nov;20(10):953-5.

123 Stacchiotti S, Marrari A, Tamborini E, Palassini E, Virdis E, Messina A, et al. Response to imatinib plus sirolimus in advanced chordoma. Ann Oncol. 2009 Nov;20(11):188694.

124 Hof H, Welzel T, Debus J. Effectiveness of cetuximab/gefitinib in the therapy of a sacral chordoma. Onkologie. 2006 Dec;29(12): $572-4$.

125 Kim S, Haas GP, Hillman GG. Development of immunotherapy for the treatment of malignancies refractory to conventional therapies. Cytokines Mol Ther. 1996 Mar;2(1): 13-9.

126 Yang Y. Cancer immunotherapy: harnessing the immune system to battle cancer. J Clin Invest. 2015 Sep;125(9):3335-7.

127 Ai L, Xu A, Xu J. Roles of PD-1/PD-L1 pathway: signaling, cancer, and beyond. Adv Exp Med Biol. 2020;1248:33-59. 
128 Feng Y, Shen J, Gao Y, Liao Y, Cote G, Choy E, et al. Expression of programmed cell death ligand 1 (PD-L1) and prevalence of tumor-infiltrating lymphocytes (TILs) in chordoma. Oncotarget. 2015 May;6(13): 11139-49.

129 Chovanec M, Cierna Z, Miskovska V, Machalekova K, Svetlovska D, Kalavska K, et al. Prognostic role of programmed-death ligand 1 (PD-L1) expressing tumor infiltrating lymphocytes in testicular germ cell tumors. Oncotarget. 2017 Mar;8(13):21794805.

130 Meng Y, Liang H, Hu J, Liu S, Hao X, Wong MS, et al. PD-L1 Expression correlates with tumor infiltrating lymphocytes and response to neoadjuvant chemotherapy in cervical cancer. J Cancer. 2018 Jul;9(16):293845.

131 Haanen JB, Robert C. Immune checkpoint inhibitors. Prog Tumor Res. 2015;42:55-66.
132 Wang J, Yang T, Xu J. Therapeutic development of immune checkpoint inhibitors. Adv Exp Med Biol. 2020;1248:619-49.

133 Migliorini D, Mach N, Aguiar D, Vernet R, Landis BN, Becker M, et al. First report of clinical responses to immunotherapy in 3 relapsing cases of chordoma after failure of standard therapies. OncoImmunology. 2017 Jun;6(8):e1338235.

134 Weber DC, Malyapa R, Albertini F, Bolsi A, Kliebsch U, Walser M, et al. Long term outcomes of patients with skull-base low-grade chondrosarcoma and chordoma patients treated with pencil beam scanning proton therapy. Radiother Oncol. 2016 Jul;120(1): 169-74.

135 Kamrin RP, Potanos JN, Pool JL. An evaluation of the diagnosis and treatment of chordoma. J Neurol Neurosurg Psychiatry. 1964 Apr;27(2):157-65.

136 Di Maio S, Temkin N, Ramanathan D, Sekhar LN. Current comprehensive management of cranial base chordomas: 10-year meta-analysis of observational studies. J Neurosurg. 2011 Dec;115(6):1094-105.
137 Chambers PW, Schwinn CP. Chordoma. A clinicopathologic study of metastasis. Am J Clin Pathol. 1979 Nov;72(5):765-76.

138 Volpe R, Mazabraud A. A clinicopathologic review of 25 cases of chordoma (a pleomorphic and metastasizing neoplasm). Am J Surg Pathol. 1983 Mar;7(2):161-70.

139 Yasuda M, Bresson D, Chibbaro S, Cornelius JF, Polivka M, Feuvret L, et al. Chordomas of the skull base and cervical spine: clinical outcomes associated with a multimodal surgical resection combined with proton-beam radiation in 40 patients. Neurosurg Rev. 2012 Apr;35(2):171-82.

140 Bohman LE, Koch M, Bailey RL, Alonso-Basanta M, Lee JY. Skull base chordoma and chondrosarcoma: influence of clinical and demographic factors on prognosis: a SEER analysis. World Neurosurg. 2014 Nov;82(5): 806-14. 